\title{
Formação Ética na Educação Profissional, Científica e Tecnológica
}

Vinícius Bozzano Nunes' Leonardo Lemos de Souza"

UniversidadeEstadual Paulista Júlio de Mesquita Filho (UNESP), Marília/SP-Brasil "Universidade Estadual Paulista Júlio de MesquitaFilho (UNESP),Assis/SP-Brasil

RESUMO - Formação Ética na Educação Profissional, Científica e Tecnológica. O descompasso entre desenvolvimento tecnológico e desenvolvimento humano é evidente na Rede Federal de Educação Profissional, Científica e Tecnológica, fazendo da formação ética um importante ponto de discussão nesse contexto. Este artigo traz resultados de pesquisa que investigou como essa formação está representada na fala dos gestores pedagógicos da Rede. Dos dados, destacam-se a tônica nas abordagens disciplinares e as representações profissionais ou profissionalizantes da ética empresarial e neoliberal. Conclui-se que o tema moralidade deve integrar os debates sobre a Educação Profissional, reconciliando as dimensões técnica e humana da formação e assim orientando o processo educativo em direção emancipatória.

Palavras-chave: Educação Profissional, Científica e Tecnológica. Formação Ética. Educação Moral. Barbárie. Representações.

ABSTRACT - Ethical Formation in Professional, Scientific and Technological Education. The mismatch between technological development and human development is evident in the Federal Network of Professional, Scientific and Technological Education, making ethical formation an important point of discussion in this context. This article shows results of research that investigates how this education is represented in the speech of the pedagogical managers of the Network. From the data, the emphasis is on disciplinary approaches and professional or professionalizing representations of business and neoliberal ethics. It is concluded that the morality theme should integrate the debates about Professional Education, reconciling the technical and human dimensions of formation and thus guiding the educational process toward emancipatory.

Keywords: Professional, Scientific and Technological Education. Ethical Education. Moral Education. Barbarism. Representations.

Educação \& Realidade, Porto Alegre, v. 43, n. 2, p. 711-726, abr./jun. 2018. 711 http://dx.doi.org/10.1590/2175-623667554 
Formação Ética na Educação Profissional, Científica e Tecnológica

\section{Introdução}

Ao passo em que nos desenvolvemos instrumentalmente em proporções nunca imaginadas na história da civilização, conservamos traços de um impulso autodestrutivo que se traveste em ignorância, intolerância e ódio, distanciando-nos de um ideal de desenvolvimento humano que acompanhe o ritmo em que se propulsiona o tecnológico. Com a atribuição de características desse tipo, tão pertinentes ao caso da humanidade contemporânea, é que em 1969, Adorno (1995) falou sobre o conceito de barbárie. Para este artigo, são capitais esse conceito e o entendimento de que os objetivos da educação devem converter-se todos no sentido de impedir que a barbárie se estabeleça.

A educação que dessa tarefa se ocupa não está restrita ao desempenho de um papel meramente instrutivo. Kant (1996) afirmava que a educação moderna precisaria aliar a instrução científica à formação ética, sob o risco de nos extinguirmos. As principais diretrizes educativas nacionais (Brasil, 1996; 1997; 2012), que também norteiam a Educação Profissional, Científica e Tecnológica (EPCT), mostram que as premissas da educação contemporânea incorporam a dimensão ética da formação, a qual considera que o processo educativo está além da instrução.

O desenvolvimento tecnológico possui caráter central na garantia da continuidade da existência humana. Isso se demonstra tanto em relação à produção de riquezas de ordem material, quanto no que diz respeito à execução de direitos sociais básicos, como saúde, alimentação, educação, entre outros. Comungando desse entendimento, encontram-se as políticas públicas brasileiras para a educação profissional, em especial as que floresceram entre os anos de 2003 e 2015, momento em que governos de natureza progressista e popular investiram fortemente no setor com vistas a posicionar o Brasil entre as principais potências econômicas do mundo, com olhar para redução de desigualdades sociais (Pacheco, 2011).

O conceito de barbárie adorniano permite problematizar uma interseção no seio da educação profissional: a formação ética. E foi essa a razão pela qual neste trabalho está manifesto o interesse por investigar as experiências em formação ética realizadas na Rede Federal de EPCT.

Se tal formação ética é um dos fins da educação nacional (Brasil, 1996), a pergunta que provocou a necessidade de investigação foi: como ela tem sido levada a cabo na EPCT, em que os holofotes se fixam em direção à corrida tecnológica? Mais além: como as unidades da Rede Federal de EPCT cumprem a exigência imposta pela legislação e pelos documentos norteadores e, a partir disso, buscam superar esse aparente paradoxo? Enfim, como ocorre a formação ética na Rede de EPCT? Responder a essa última questão foi o principal propósito desta pesquisa.

A formação ética, sob as mais diversas concepções e modos de fazer, acontece em toda e qualquer escola, pois "[...] a influência moral sobre os alunos é impossível de ser evitada no ambiente escolar" (Goergen, 2007). O norte paradigmático adotado neste estudo, contudo, não 
se ajusta ao relativismo absoluto, motivo pelo qual foi necessário forjar uma concepção para formação ética que se ancorasse nas teorias filosófica e pedagógica e que, ao mesmo tempo, distinguisse em nome de que tipo de formação ética aqui se fala.

Assim, partimos da elaboração do conceito de formação ética com base no debate sobre ética e moral que introduz Sánchez Vázquez (2002). Ele entende que a moral reside no campo prático. É termo relativo ao comportamento moral, ao plano concreto. Ética, por outro lado, é "[...] teoria ou ciência do comportamento moral dos homens em sociedade” (Sánchez Vázquez, 2002, p. 23). No entanto, tal definição esbarra na crítica à dicotomia teoria/prática. Como expõe Sánchez Vázquez, a dimensão ética é própria dos filósofos e pensadores da moral. Já a moral, menos complexa e mais corriqueira, cabe ao indivíduo comum (Sánchez Vázquez, 2002).

Contestando o caráter binário desse postulado, incorporou-se a este conceito elementos buscados da moralidade comunicativa (Habermas, 2003). Essa teoria compreende a moralidade como constructo coletivo originado a partir de cada situação singular de argumentação moral em que se tende à universalidade por meio de consensos livremente acordados. Entendida desse modo, a ação moral é possível a todo e qualquer agente inserido em um contexto de argumentação moral, não somente aos filósofos ou pensadores da moral. Compreender a moralidade dessa maneira implica concordar com Habermas em sua denúncia da filosofia como guardadora de lugar de outros conhecimentos (Habermas, 2003), como as artes, a ciência e, no caso que nos interessa, a ética.

Além das postulações de Sánchez-Vázquez (2002) e Habermas (2003), trabalhos de Piaget (1996; 1994), Kohlberg (1984), junto a outras publicações recentes de pesquisadores brasileiros, serviram de base para a elaboração do conceito de formação ética. Entre eles, estão alguns dos que discorrem sobre formação ética, educação moral e educação em valores (Arantes; Araújo; Puig, 2007; Freitag, 1992; Gallo, 2010; Goergen, 2001; 2005; 2007; 2010; Kohlberg, 1984; La Taille, 2006; 2009; La Taille; Menin, 2009; Menin, 2002; Menin; Bataglia; Zechi, 2013; Menin et al., 2014; Piaget, 1994; 1996), indisciplina escolar (Aquino, 1996; Garcia, 2009; Lepre, 2009), entre outros também importantes e relacionados ao tema desta pesquisa.

O conjunto de debates promovidos por esses autores iluminou a construção de uma base conceitual para a locução formação ética sobre a qual este estudo está apoiado. Assim, compreende-se a formação ética como aquela que se realiza de modo planejado e organizado e que tem como fim a reflexão crítica sobre e na ação moral concreta, sendo possível a todos os indivíduos. Essa reflexão rompe com o plano unidimensional do pensamento, concretizando-se a partir da ação a ela integrada. É construída comunicativamente na interação entre sujeitos que assumem papel ativo nesse processo e que buscam um consenso tendente à universalização, distanciando-se da relativização absoluta. 
Formação Ética na Educação Profissional, Científica e Tecnológica

Orienta-se no sentido da busca pela autonomia, de forma cada vez mais ampla e complexa e está relacionada intimamente à ideia de cidadania. Perpassa todos os ambientes e contextos escolares. Está na sala de aula, assim como está nas relações que se estabelecem na escola ou por meio dela. Pode ser concretizada por intermédio de distintas metodologias, desde que estas estejam integradas em projetos escolares mais abrangentes e em que haja participação ampla da comunidade escolar. Diante de sua importância, a formação ética deve ser tomada como principal finalidade da educação escolar.

Exposta a questão, o objetivo geral e a concepção de formação ética tomada por eixo na pesquisa, antes de apresentar os métodos, cabe definir o recorte adotado na pesquisa. Este texto integra um estudo maior que buscou compreender como ocorre a formação ética na EPCT. Para tanto, abordaram-se múltiplas dimensões da questão, o que se fez por meio de um formulário com 18 questões. Dessas, foram destacadas para este caso as três primeiras: a) As unidades da Rede de EPCT devem oferecer uma formação ética a seus estudantes? b) Por que pensam que a formação ética deveria ser ou não ofertada pelas unidades da Rede de EPCT? c) Como essa formação deve ocorrer? As três questões dizem respeito, respectivamente, às representações dos gestores pedagógicos que responderam ao formulário sobre a necessidade da formação ética, aos motivos e razões para que aconteça e a como a idealizam do ponto de vista metodológico.

Aqui será adotado o termo representações sociais na esteira do que Menin et al. (2014) elegem como ideal em estudo que teve essa mesma natureza. Acompanhando Moscovici (1978), Menin e demais pesquisadores entendem como representação social:

\begin{abstract}
[...] formas de conhecimento prático construídas coletivamente, na comunicação informal e nas práticas sociais sobre certos objetos, as quais levam as marcas dos grupos e da cultura onde se originam. Surgem, normalmente, a partir de certas pressões provocadas pelo meio social a respeito de um objeto novo, que causa estranhamento e precisa ser explicado [...] (Menin et al., 2014, p. 136).
\end{abstract}

Para os autores, a pressão contemporânea por respostas no campo da educação moral justifica o uso da teoria das representações sociais. Com o que concordamos, resguardadas as controvérsias sobre os diferentes usos do termo representações, em especial no campo de estudos que trata dos níveis de compreensão da realidade social.

\title{
Métodos
}

A elaboração do instrumento de coleta de dados teve como ponto de partida a adaptação do questionário utilizado na pesquisa Projetos bem Sucedidos em Educação Moral: em busca de experiências brasileiras, realizado por um grupo de pesquisadores vinculados à ANPEPP - Associação Nacional de Pesquisa e Pós-Graduação em Psicologia (Menin; Bataglia; Zechi, 2013; Menin et al., 2014). As poucas adaptações que se 
fizeram necessárias tiveram base em revisão bibliográfica e na caracterização em função das peculiaridades da EPCT. Como recorte, foi escolhido o período compreendido entre 2003 e 2013, década em que novas políticas impactaram a educação profissional brasileira.

O instrumento foi elaborado e encaminhado utilizando-se a plataforma Surveymonkey. As unidades da Rede de EPCT já implantadas foram participantes da pesquisa. Excluíram-se aquelas unidades que se encontravam em processo de implantação, visto que algumas delas contavam apenas com o aparato administrativo, sem que já tivessem iniciado suas ações pedagógicas, sendo que, por isso, deixaram de integrar universo de interesse do estudo.

As informações disponíveis na página da Rede Federal de EPCT na internet serviram como fonte para a seleção das unidades participantes da pesquisa. Nas situações de indefinição das informações sobre o processo de implantação, buscou-se o endereço web das instituições e contato telefônico para confirmação dos dados. Das 382 unidades identificadas, foi possível o contato efetivo com 297. Encaminharam-se os formulários de pesquisa a todas as Unidades da Federação, endereçado aos gestores pedagógicos (coordenadores pedagógicos, gestores educacionais, diretores de ensino, entre outras nomenclaturas atribuídas a essa mesma função). Houve 106 termos de consentimento livre e esclarecido preenchidos. Desses, foram considerados apenas os preenchimentos válidos, o que correspondeu a 69 participantes (23,2\%). Do novo número, houve pelo menos um campus participante em cada estado, atendendo à expectativa de abrangência territorial da pesquisa.

As respostas às questões objetivas foram tabuladas e analisadas quantitativamente. Às questões de resposta discursiva, fossem elas independentes ou complementares em relação às quantitativas, o tratamento dado foi o qualitativo. A leitura e a análise dos dados de ordem qualitativa foram realizadas utilizando-se a triangulação como método (Denzin apud Flick, 2009). Por essa via, os dados coletados, a revisão bibliográfica e a análise documental foram entretecidos, dando o suporte necessário às análises de cunho interpretativo.

Os sujeitos da pesquisa foram identificados como participantes, representando as unidades integrantes da Rede de EPCT. Foram elas as Escolas Técnicas vinculadas às Universidades Federais, os CEFET's, o Colégio Pedro II, a Universidade Tecnológica Federal do Paraná, juntamente com os novos Institutos Federais (Brasil, 2008). Tecidas as considerações metodológicas, encaminhamo-nos à apresentação, análise e discussão dos dados obtidos.

\section{Sobre a Formação Ética na Rede de Educação Profissional, Científica e Tecnológica}

A primeira indagação feita foi se pensam os gestores que as unidades da Rede de EPCT devem oferecer uma formação ética a seus estudantes. As respostas obtidas permitiram que fossem interpretadas sob 
Formação Ética na Educação Profissional, Científica e Tecnológica

dois aspectos: se se conhece em algum grau a importância dessa formação e se os gestores acreditam que a escola seja o/um local apropriado para que nela se desenvolva essa formação.

A resposta positiva foi unânime e indica que o conhecimento reunido nas unidades da Rede de EPCT sobre a importância da formação ética é de que, em termos de resultado pedagógico, ela não é negativa nem nula, mas benéfica. Da mesma maneira, pode-se inferir que, em suas representações, os gestores pensam ser a escola um espaço adequado para essa formação. Diante de uma crise de valores na contemporaneidade (La Taille; Menin, 2009) a formação ética, além de passível de realização, é entendida pelos participantes como necessária. Esse resultado se assemelha ao que Menin et al. (2014) encontraram em 99\% das 1033 escolas públicas brasileiras que estudaram.

A tendência à resposta positiva nesse caso pode ter origem diversa. Uma das possiblidades seria a ancoragem no que preconiza a legislação. No entanto, apenas a Lei 9.394/96, que estabelece as Diretrizes e Bases da Educação Nacional e se aplica também à EPCT, aborda diretamente a questão. Como consta no inciso III de seu artigo 35, que trata das finalidades da educação, a formação ética é um dos elementos necessários ao "[...] aprimoramento do educando como pessoa humana" (Brasil, 1996, art. 35).

A mesma contundência não é vista nas Diretrizes Curriculares Nacionais para a Educação Técnica de Nível Médio (Brasil, 2012), tampouco na Lei de criação dos Institutos Federais, 11.892/08. Nesta, um mero aceno em direção a uma preocupação ética se vê em uma de suas descritas finalidades: "[...] promover a produção, o desenvolvimento e a transferência de tecnologias sociais, notadamente as voltadas à preservação do meio ambiente" (Brasil, 2008, p. 4).

Não havendo diretrizes, programas, projetos que prevejam ou delineiem claramente ações que efetivem a formação ética na EPCT, é curioso que todos os gestores tenham estendido à educação profissional a responsabilidade pela oferta dessa formação. O que daí se percebe é que a formação ética acontece na escola mesmo não havendo previsão legal, documental ou ainda programa ou projeto de qualquer natureza em que se tenha consolidado no âmbito da EPCT, confirmando tese apresentada por Goergen (2007). No entanto, sem diretrizes que forneçam pistas ontológicas, epistemológicas ou metodológicas para essas práticas, é inevitável que elas ocorram segundo critérios próprios, levadas a cabo de modo desarticulado, não sistematizado, segundo parâmetros estabelecidos de modos mais ou menos democráticos, enfim, sem nítido balizamento.

Em consonância com essa constatação, ao responder a questão complementar: Por que pensam que a formação ética deveria ser ou não ofertada pelas unidades da Rede de EPCT?, as razões apresentadas foram diversas. Todos os que se manifestaram fizeram menção a um determinado fim da educação que estaria sendo cumprido por meio da oferta da formação ética. Por isso, as respostas foram agrupadas nas seguintes

716 Educação \& Realidade, Porto Alegre, v. 43, n. 2, p. 711-726, abr./jun. 2018. 
categorias: a) formação humana; b) formação profissional; e c) formação integral. Houve participantes que não responderam e, outros, cuja resposta não pôde ser classificada em nenhuma das categorias, pois não ofereceu recurso suficiente para tal, dada a pouca e/ou desconexa informação apresentada.

\section{Gráfico 1 - Por Que a Formação Ética Deve ser Ofertada pelas Unidades da Rede de EPCT?}

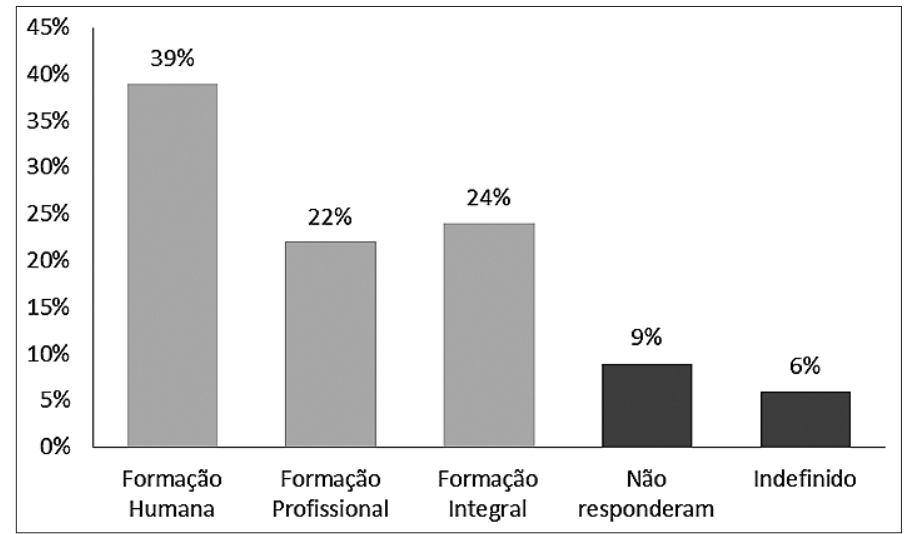

Fonte: Elaborado pelos autores.

Vê-se (Gráfico 1) que o grupo que atribui a importância da oferta da formação ética à dimensão humana da formação educacional soma 27 das unidades participantes (39\%). Os que atribuem tal importância à formação para a atuação profissional são 15 (22\%). Já os que compreendem que seja devido à necessidade de que os Institutos Federais promovam uma educação integral, são 17 (24\%). As respostas nulas ou impossíveis de serem categorizadas totalizaram $15 \%$.

Formação humana, para este estudo, é aquela inspirada nos Parâmetros Curriculares Nacionais (PCN's) que visa à formação plena do indivíduo como ser humano (Brasil, 1997). Por essa concepção, a formação ética seria compreendida como formação para a vida, para os relacionamentos entre as pessoas, para uma melhor convivência, para a participação social e política, para a cidadania. De modo geral, a formação humana de que tratamos se resume nos esforços educativos voltados ao preparo do indivíduo para a vida, sem que haja menções explícitas à dimensão profissional.

Mostram mais claramente o teor comum desta categoria:

Primeiramente, porque os Parâmetros Curriculares Nacionais sinalizam que a educação escolar deve propiciar o aluno a compreender a cidadania como participação social e política além de posicionar-se de maneira crítica, responsável e construtiva diante de situações conflituosas, isso automaticamente implica ética e cidadania. A instituição educacional tem papel relevante na formação ética e de cidadania, visto a extensão da transformação da educação na vida dos alunos (Participante 3, 2014). 
Formação Ética na Educação Profissional, Científica e Tecnológica

Um dos objetivos dos IF's é o aprimoramento da cidadania plena na vida em sociedade. Aética é um componente fundamental da sociedade brasileira atual (Participante 39, 2014).

Devido à necessidade de formação de cidadãos críticos, reflexivos e capazes de construir uma nova sociedade baseada nos valores humanos: Paz, Justiça, Solidariedade, Não-Violência, Verdade (Participante 50, 2014).

A representação majoritária da formação ética como integrante do projeto de formação humana nos Institutos Federais permite considerar que há uma preocupação evidente em se reforçar a ideia de educação não instrumentalizante. Dizer isso implica atribuir maior relevo à dimensão humana do processo educativo, em detrimento de um projeto de sujeito cuja sina seja tornar-se produtivo dentro de uma lógica econômica, o que acabaria por se tornar condição de sua existência.

O apelo a princípios explícitos nos PCN's (1997), como feito pelo participante 3, aponta a importância que esse instrumento tem na formação de representações sobre educação por parte dos gestores. Encontra-se aí um indicativo de sucesso na propagação e alcance desse instrumento orientador das práticas educativas no país. Por outro lado, destaca-se a falta de diretrizes específicas para a EPCT que deem conta de suas peculiaridades, como, por exemplo, o direcionamento às questões do mundo do trabalho e as demandas por ciência, tecnologia e inovação, tão veementemente instigadas em seus projetos de formação.

Como formação profissional - ou formação ética enquanto parte integrante da formação para a atuação profissional -, foram classificadas todas as respostas que apontaram estritamente para a importância da ética no campo do trabalho. A expressão dessa representação por alguns participantes mostra que, para eles, a função da ética é a de integrar o currículo dos profissionais que irão da escola para o mercado de trabalho. A formação ética, nesse caso, teria a função de balizar as relações laborais, de conduzir a comportamentos adequados e desejados pelo mercado de trabalho, contribuindo para a formação do perfil profissional mais alinhado às expectativas sociais no que tange ao bom desenvolvimento dos negócios.

Alguns exemplos de falas nesse sentido:

Como sairão direto para o mercado de trabalho, é muito importante que esses jovens já estejam prontos também neste quesito (Participante 22, 2014).

Formamos profissionais e se não contemplarmos uma formação ética durante o processo educacional o que poderemos esperar desses profissionais?(Participante 34, 2014).

Porque os técnicos, tecnólogos e professores que os Institutos Federais estão formando precisam ter uma formação ética, tendo em vista que vão trabalhar com recursos humanos (Participante 54, 2014).

Tais respostas se diferenciam das que prezam pela formação humana. Isso se faz notar pelo fato de que privilegiam a dimensão profissional, evidenciando o enfoque no atendimento às demandas do mercado de trabalho. Portanto, é possível identificar nessas falas a representação da formação ética como algo cujo propósito principal é 
produzir um comportamento desejável pelo mercado. A Lei 11.892/08 é nebulosa acerca da questão ética e da inclinação ao atendimento às demandas do mercado de trabalho. Nos comentários à Lei, Pacheco (2011) busca dirimir esse problema. Diz que o projeto de Educação Profissional atual se contrapõe aos anseios das políticas neoliberais globalizantes. Ainda, que o Brasil luta para se desvencilhar dos problemas gerados por vinte anos de privatizações e que um projeto democrático que se construiu coletivamente não pode se curvar a interesses particulares.

\begin{abstract}
Recusamo-nos a formar consumidores no lugar de cidadãos, a submeter a educação à lógica do capital, colocando o currículo como instrumento do simples treinamento de habilidades e técnicas a serviço da reprodução capitalista (Pacheco, 2011, p. 7).
\end{abstract}

Ocorre que o dispositivo legal, mesmo discutido por textos complementares à Lei, carrega em si sinalizações diferentes, que apontam para direções mais vinculadas a uma educação instrumentalizante que humanizadora. Mas, se é possível falar em ética tanto pela perspectiva humanizadora quanto do ponto de vista profissionalizante, o que pensar quando os propósitos desses dois modelos se contradizem? Segundo Paulo Freire (1996, p. 9) nós, “[...] educadores e educandos, não podemos, na verdade, escapar à rigorosidade ética. Mas, é preciso deixar claro que a ética de que falo não é a ética menor, restrita, do mercado, que se curva obediente aos interesses do lucro". O pensamento de Paulo Freire nos auxilia trazendo a compreensão de que existem duas éticas fundamentalmente antagônicas: uma neoliberal e, outra, a ética universal do ser humano (Freire, 1996).

Sensíveis ao apelo geral por eticidade, as corporações apropriam-se do conceito ética e passam a adotar essa palavra como algo capaz de agregar valor. Com essa roupagem, o termo ética surge eufemizado na composição da linguagem corporativa e publicitária, porém, imbuído agora de outra espécie de valor, o econômico.

Ouço muito dizer, aqui e ali, leio na imprensa, tanto profissional como para o grande público, observações como estas: 'A ética (subentendido, nesse contexto, a ética empresarial) melhora o clima interno da empresa, logo a produtividade'; 'A ética melhora a imagem da empresa, logo as vendas'; 'A ética melhora a qualidade da produção ou do serviço, logo, de novo, as vendas' [...] Resumindo, a ética é eficiente, a ética vende! 'Ethics pays' [...] Alguns chegam a forjar o curioso neologismo 'markética', para designar o filho, bizarramente formado, dos estranhos amores entre o marketing e a ética [...] (Comte-Sponville, 2011, p. 42).

No discurso do senso comum, essa confusão é corriqueira. No entanto, ética não é termo neutro. Uma formação ética que eleja a competição como principal pauta e que valorize atitudes que se alinhem ao sucesso dos negócios assume o discurso da ética neoliberal ou empresarial em detrimento da ética universal do ser humano. Vai assim de encontro à concepção de formação ética tomada por norte deste estudo. 
Formação Ética na Educação Profissional, Científica e Tecnológica

A resposta do Participante 54 exemplifica a dicotomia entre tipos de formação. Em sua fala, a ética é representada como necessária à dimensão profissional, porque os futuros trabalhadores se depararão com situações em que terão que lidar com recursos humanos, ou seja, no trato com pessoas. Isso exclui um entendimento da ética em um sentido mais amplo, como condição para que o indivíduo veja e atue no mundo de forma crítica e reflexiva, tanto no que tange às questões próprias do trabalho - em uma perspectiva macro - como quanto ao seu papel no desenvolvimento da ciência e da tecnologia e nos rumos a que esse desenvolvimento pode levar enquanto humanidade.

Por fim, a última categoria originada pela análise das respostas à segunda questão é a da formação integral. É certo que esse termo tem figurado na linguagem corrente das pesquisas em educação revestido de diversos sentidos. Neste estudo, contudo, utilizamos um deles. Aqui, o conceito é compreendido como sendo a formação que articula duas dimensões, humana e profissional. Nessa perspectiva, a dimensão do trabalho é considerada como integrante do processo formativo, aproximando-se conceitualmente das discussões sobre a ideia de integração na EPCT. Segundo Ramos (2008), essa integração é profunda e ampla, mais que mera articulação. Na EPCT, ela tem três sentidos: o da formação omnilateral, o da indissociabilidade entre educação profissional e educação básica e o da integração de conhecimentos gerais e específicos.

Dos participantes, $17 \%$ atribuíram a necessidade da oferta de Formação Ética na EPCT ao entendimento de que essa formação é elemento necessário para uma formação integral, ou integrada. Destacamos algumas respostas:

O Profissional atual precisa além da formação profissional da formação humana e ética. Pois, não queremos formar meros apertadores de parafusos (Participante 2, 2014).

A ética faz parte da formação do ser humano. Um professor ao entrar na sala de aula ministra conteúdos específicos (conteúdo da Disciplina que leciona) e não específicos (atitudes, valores e habilidades) que fazem parte da formação do ser integral (Participante 55, 2014).

A Educação Profissional que deve ser ofertada aos alunos atualmente deve ser pensada em uma formação integral do indivíduo, e não mais no preparo de mão de obra para o mercado de trabalho, partindo desse pressuposto, não existe formação integral sem abordagem ética (Participante 64, 2014).

Esse tópico ilustra a emergente questão no âmbito da EPCT que é a da integração. Muito embora o conceito de integração não esteja expresso na Lei 11.892/08, sua discussão fica mais visível nos documentos de nível mais teórico, como o Documento Base para a EPCT (Brasil, 2007) que precedeu a promulgação da Lei citada, entretanto, parecendo não a ter influenciado. Mesmo assim, o conceito de integração atravessa a fala de alguns participantes. O participante 55 traz em sua fala a ideia de integração entre conhecimentos gerais e específicos e, em acordo com o participante 2 , dá a entender que educação básica e educação 
profissional são dimensões indissociáveis. O participante 64 reforça a formação integral como razão para que a formação ética seja ofertada na EPCT, realçando o sentido da formação omnilateral (Ramos, 2008).

O participante conclui com uma interessante afirmação: não há formação integral sem formação ética. Os subsídios teóricos de que se lança mão para embasar esta pesquisa ratificam essa ideia. Desse modo, acredita-se que a contribuição que os resultados deste estudo fornecem aos debates sobre integração na EPCT é a de que a formação ética deve, neles, tomar lugar central e não apenas constituir-se como apêndice da dimensão cultural na tríade trabalho, ciência e cultura, que representa o sentido omnilateral do termo integração.

Retomando as questões anteriores, vê-se que há unanimidade sobre a necessidade da oferta da formação ética na EPCT. Quanto às razões para que essa oferta ocorra, já não vemos tanta homogeneidade nas respostas. Quando analisamos os resultados da terceira e última questão - como essa formação deve ocorrer? -, a diversificação nas respostas é ainda maior.

Sua análise forneceu subsídios para a criação das seguintes subcategorias: a) abordagem curricular (disciplinas); b) exemplos dos servidores; c) ações de extensão; e d) integração de métodos. Além dessas, algumas respostas não puderam ser categorizadas por oferecerem informação insuficiente e/ou desconexa e, outros participantes, não responderam à questão.

\section{Gráfico 2 - Como deve Ocorrer a Formação Ética na EPCT?}

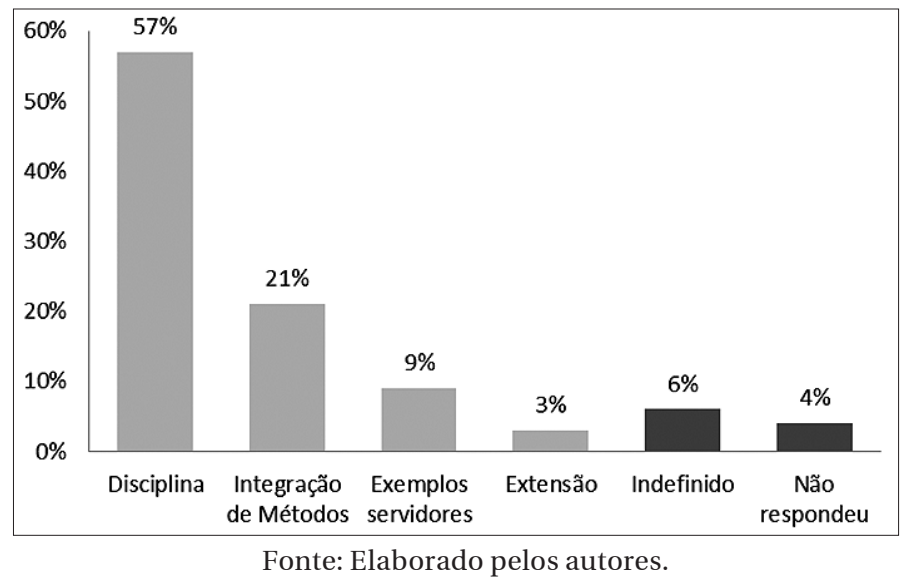

Neste tópico (Gráfico 2) não se tratou de discorrer sobre como são desenvolvidos os projetos de formação ética nos Institutos, mas sim, sobre como os gestores pensam que eles deveriam ocorrer. Dito isso, $57 \%$ (39) entendem que a formação ética deve acontecer por meio de disciplinas; 9\% (6) indiretamente, por exemplos dos servidores da instituição; $3 \%$ (2) por atividades de extensão, como palestras ou cursos; e $21 \%$ (14) dizem que os projetos de formação ética deveriam integrar mais de um método, incluindo os citados em outras categorias. 
Formação Ética na Educação Profissional, Científica e Tecnológica

O contraste com a pesquisa de Menin et al. (2014), apesar de algumas diferenças de ponto de vista no que diz respeito à elaboração de categorias, mostra algumas aproximações interessantes. Na Rede de EPCT, a abordagem disciplinar corresponde naquela pesquisa à categoria espaço: disciplinas e ou temas transversais, com os percentuais de $57 \%$ e $43,99 \%$, respectivamente. Os exemplos, por sua vez, remetem à categoria papel dos responsáveis, correspondendo a $9 \%$ e 16,25\%. Integração entre métodos e atividades de extensão, somadas, correspondem no estudo das escolas públicas brasileiras à categoria estratégias diversificadas, o que em percentual representa $24 \%$ das respostas daqueles e $29 \%$ destes. Ou seja, consideradas as peculiaridades da EPCT em relação à educação regular, a representação sobre como deveria acontecer a formação ética / educação moral na escola é bastante semelhante em todos os casos.

Pensar a formação ética por meio das unidades curriculares ou disciplinas remete, em último caso, a um modelo escolar tradicional, transmissionista, que afirma o conteudismo em detrimento do desenvolvimento de habilidades e competências intelectuais, afetivas e sociais. Contudo, nesse grupo de respostas são vistas algumas nuances que as diferenciam entre si e podem dar uma melhor ideia do quanto se aproximam de um ou outro entendimento sobre educação moral. Nesse caso, dentro da categoria disciplinas, há subcategorias nas quais se acomodam distintas compreensões:

\section{Gráfico 3 - Abordagens Curriculares para a Formação Ética}

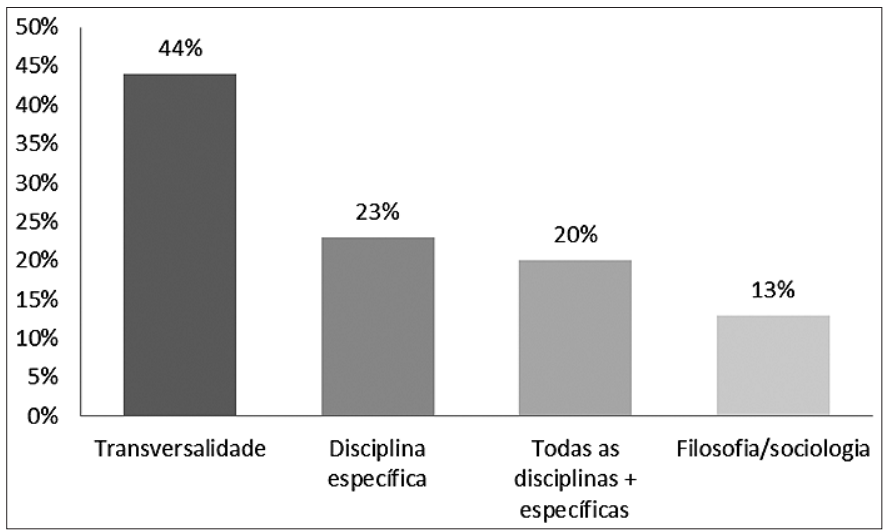

Fonte: Elaborado pelos autores.

Vemos (Gráfico 3) que, dos 39 participantes que apontam que a formação ética deve ocorrer por meio de uma abordagem curricular, 17 (44\%) entendem que deva ser de modo transversal, 9 (23\%) pela criação de uma disciplina específica que trate do tema, 8 (20\%) pensam que deve ser trabalhada em todas as disciplinas e também pela criação de uma disciplina específica e 5 (13\%) que ela esteja presente em todas as disciplinas, mas, de modo particular, nas disciplinas de filosofia e/ou sociologia. 
Os Institutos que indicaram que a formação ética deve ocorrer de modo transversal correspondem não só à maioria dentro da categoria das disciplinas, como também à maioria absoluta, em relação a outras formas de se compreender a formação ética na EPCT. Assim, é também majoritário o entendimento de que a ética, juntamente aos temas pluralidade cultural, meio ambiente, saúde, orientação sexual, trabalho e consumo, sejam desenvolvidos por meio da perspectiva da transversalidade, acompanhando os PCN's (Brasil, 1997). Alguns dos participantes que ilustram bem essa representação:

Com conteúdos transversais, destacando valores humanos e éticos (Participante 29, 2014).

Essa formação deve ter um caráter de transversalidade curricular, posto que, na minha opinião, a ética, traduzida em uma única disciplina, não consegue obter a ressonância necessária à vivência e ao esclarecimento intelectivo / pessoal entre o alunado e a comunidade escolar, como um todo (Participante 41, 2014).

Ela precisa estar presente em todas as disciplinas, como tema transversal, já previsto nos parâmetros curriculares (Participante 60, 2014).

Se os temas são realmente tão importantes à vida dos estudantes hoje e se, de fato, a escola deveria estar comprometida com tais questões, as orientações contidas no documento apresentação dos temas transversais se mostram insuficientes para o sucesso da proposição. Menin (2002) constata o laissez-faire em termo de valores na escola, sugerindo que, realizada da maneira como tem sido, a transversalidade não contribui para que esse paradigma seja rompido. Ao contrário, a omissão em relação à formação ética parece encontrar o refúgio perfeito no discurso da transversalidade, onde não há intenção, projeto, planejamento, método ou avaliação explícitos.

\section{Considerações Finais}

Os gestores pedagógicos (diretores de ensino, coordenadores pedagógicos, etc.) afirmam em uníssono que a formação ética deve ser ofertada pelas unidades da Rede Federal de EPCT de que fazem parte. Entre eles, podem ser identificadas três razões para que essa formação aconteça. Ela pode ter o propósito de garantir uma formação humana, uma formação profissional ou de servir à formação integral, que articula as duas dimensões anteriores. Como ela deve ocorrer? é a pergunta que ramifica ainda mais as respostas. A maioria responde que por meio de uma abordagem disciplinar (de modo transversal, mais do que por uma disciplina específica ou por disciplinas de filosofia ou sociologia). Não tantos pensam em estratégias que promovam a integração entre métodos, havendo também alguns poucos que apostam no exemplo dos servidores (docentes, técnicos, gestores) como estratégia mais eficaz.

Esse quadro múltiplo e difuso é sintoma da ausência de diretrizes claras que possam nortear as ações de formação ética na EPCT, de modo que a orientação mais direta vem da LDB, que tem por alcance 
Formação Ética na Educação Profissional, Científica e Tecnológica

toda a educação básica, incluída a educação profissional. A força desse dispositivo, corroborado pelos temas transversais que integram os Parâmetros Curriculares Nacionais, é o pano de fundo que sustenta grande parte das respostas dos gestores. No entanto, o modo pelo qual abordam essa formação deixa de considerar algumas importantes especificidades da EPCT em relação à educação regular. É o caso da proximidade às questões do mundo/mercado de trabalho e dos avanços científicos e tecnológicos.

A inicial concordância unívoca sobre a adequação da EPCT como lugar da formação ética converte-se, pois, em ampla diversidade ao ser mais profundamente explorado o discurso de seus atores. Nas leis e documentos norteadores, por outro lado, a previsão dessa formação é praticamente ausente. A formação ética também não é proposta pela via do pensamento progressista que sugere à EPCT novos ares. Como exemplo disso, o debate sobre o conceito de integração - que se tem tornado importante no cenário da nova EPCT - a coloca em segundo plano, constituindo apenas parte da dimensão cultura que, junto ao trabalho e à ciência, compõem o sentido omnilateral do termo integral.

Atribuir à formação ética esta dimensão cultural da formação integral é ação pouco integrativa, dado que se funda ainda neste modelo disciplinar do processo de escolarização, próprio da modernidade técnica. O desejável é que, assim como em palavras o fez Buarque (1993), que a pirâmide em que se põe no alto a modernidade técnica seja invertida, convertendo seu ápice em modernidade ética. Para tanto, é preciso que a vanguarda dos debates trate a ética como conceito capital e não transversal. Que os frutos dessas reflexões sobre a EPCT inspirem leis, diretrizes, programas e projetos. Por fim, que a partir disso, no cotidiano educacional, seja possível reordenar os objetivos da EPCT com o propósito de reconciliar desenvolvimento humano e tecnológico e, desse modo, educar contra a barbárie.

Recebido em 02 de setembro de 2016 Aprovado em 08 de setembro de 2017

\section{Referências}

ADORNO, Theodor Ludwig Wiesengrund. Educação e Emancipação. Tradução: Wolfgang Leo Maar. Rio de Janeiro: Paz e Terra, 1995.

AQUINO, Julio Groppa (Org.). Indisciplina na Escola: alternativas teóricas e práticas. São Paulo: Summus, 1996.

ARANTES, Valéria Amorim; ARAÚJO, Ulisses Ferreira de; PUIG, Josep Maria. Educação em Valores: pontos e contrapontos. São Paulo: Summus, 2007.

BRASIL. Ministério da Educação. Lei no. 9.394, de 20 de dezembro de 1996. Estabelece as Diretrizes e Bases da educação nacional. Diário Oficial da União, Brasília, 23 dez. 1996. P. 1. Disponível em: <http://www.planalto.gov.br/ccivil_03/ leis/L9394.htm>. Acesso em: 08 ago. 2016.

BRASIL. Ministério da Educação. Parâmetros Curriculares Nacionais: apresentação dos temas transversais e ética. Brasília: MEC, 1997.

724 Educação \& Realidade, Porto Alegre, v. 43, n. 2, p. 711-726, abr./jun. 2018. 
BRASIL. Ministério da Educação. Documento Base da Educação Profissional Técnica de Nível Médio Integrada ao Ensino Médio. Brasília: SETEC, 2007. Disponível em: <http://portal.mec.gov.br/setec>. Acesso em: 07 ago. 2016.

BRASIL. Ministério da Educação. Lei no 11.892, de 29 de dezembro de 2008. Institui a Rede Federal de Educação Profissional, Científica e Tecnológica, cria os Institutos Federais de Educação, Ciência e Tecnologia e dá outras providências. Diário Oficial da União, Brasília, 30 dez. 2008. Disponível em: <http://www.planalto. gov.br/ccivil_03/_ato2007-2010/2008/lei/111892.htm>. Acesso em: 08 ago. 2016.

BRASIL. Ministério da Educação. Resolução No 6, de 20 de setembro de 2012. Define Diretrizes Nacionais para a Educação Profissional Técnica de Nível Médio. Diário Oficial da União, Brasília, 21 set. 2012. Disponível em: <http://portal. mec.gov.br/index.php?option=com_docman\&view=download\&alias=11663rceb006-12-pdf\&category_slug=setembro-2012-pdf\&Itemid=30192>. Acesso em: 08 ago. 2016.

BUARQUE, Cristovam. Da Modernidade Técnica à Modernidade Ética. In: CONSELHO FEDERAL DE MEDICINA. Desafios Éticos. Brasília: CFM, 1993. P. 20-24.

COMTE-SPONVILLE, André. O Capitalismo é moral? sobre algumas coisas ridículas e as tiranias do nosso tempo. Tradução: Eduardo Brandão. 2. ed. São Paulo: WMF Martins Fontes, 2011.

FLICK, Uwe. Uma Introdução à Pesquisa Qualitativa. Tradução: Sandra Netz. 2. ed. Porto Alegre: Artmed, 2009.

FREIRE, Paulo. Pedagogia da Autonomia: saberes necessários à prática educativa. 25. ed. São Paulo: Paz e Terra, 1996.

FREITAG, Barbara. Itinerários de Antígona: a questão da moralidade. Campinas: Papirus, 1992.

GALLO, Sílvio. Filosofia, Educação e Cidadania. In: PEIXOTO, Adão José (Org.). Filosofia, Educação e Cidadania. 3. ed. Campinas: Alínea, 2010. P. 133-153.

GARCIA, Joe. Representações dos Professores sobre Indisciplina Escolar. Educação, Santa Maria, v. 34, n. 2, p. 311-324, 2009.

GOERGEN, Pedro. Educação Moral: adestramento ou reflexão comunicativa? Educação \& Sociedade, Campinas, v. 22, n. 76, p. 147-174, out. 2001.

GOERGEN, Pedro. Educação e Valores no Mundo Contemporâneo. Educação \& Sociedade, Campinas, v. 26, n. 92, p. 983-1011, out. 2005.

GOERGEN, Pedro. Educação Moral Hoje: cenários, perspectivas e perplexidades. Educação \& Sociedade, Campinas, v. 28, n. 100, p. 737-762, out. 2007.

GOERGEN, Pedro. Educação Moral e Cultura. Estudos de Sociologia [on-line], Araraquara, v. 15, n. 28, p. 159-175, jan./jun. 2010.

HABERMAS, Jürgen. Consciência Moral e Agir Comunicativo. 2. ed. Rio de Janeiro: Tempo Brasileiro, 2003.

KANT, Immanuel. Sobre a Pedagogia. Tradução: Francisco Cock Fontanella. Piracicaba: UNIMEP, 1996. [1923].

KOHLBERG, Lawrence. Psicología del Desarollo Moral. Bilbao: Desclée de Brower, 1984.

LA TAILLE, Yves de. Moral e Ética: dimensões intelectuais e afetivas. Porto Alegre: Artmed, 2006.

LA TAILLE, Yves de. Formação Ética: do tédio ao respeito de si. Porto Alegre: Artmed, 2009.

Educação \& Realidade, Porto Alegre, v. 43, n. 2, p. 711-726, abr./jun. 2018. 
Formação Ética na Educação Profissional, Científica e Tecnológica

LA TAILlE, Yves de; MENIN, Maria Suzana de Stefano (Org.). Crise de Valores ou Valores em Crise? Porto Alegre: Artmed, 2009.

LEPRE, Rita Melissa. Reflexões sobre a Indisciplina na Escola. Psicopedagogia [Online], São Paulo, v. 1, p. 01-10, 2009.

MENIN, Maria Suzana de Stefano et al. Os Fins e Meios da Educação Moral nas Escolas Brasileiras: representações de educadores. Revista Portuguesa de Educação, Coimbra, v. 27, p. 133-155, 2014.

MENIN, Maria Suzana de Stefano. Valores na Escola. Educação \& Pesquisa, São Paulo, v. 28, n. 1, jun. 2002. Disponível em: <http://www.scielo.br/scielo.php? script=sci_arttext\&pid=S1517-97022002000100006\&lng=en\&nrm=iso $>$. Acesso em: 08 ago. 2016.

MENIN, Maria Suzana de Stefano; BATAGLIA, Patricia Unger Raphael; ZECHI, Juliana Aparecida Matias (Org.). Projetos Bem-Sucedidos de Educação em Valores: relatos de escolas públicas brasileiras. São Paulo: Cortez, 2013.

MOSCOVICI, Serge. A Representação Social da Psicanálise. Rio de Janeiro: Zahar, 1978.

PACHECO, Eliezer (Org.). Institutos Federais: uma revolução na educação profissional e tecnológica. São Paulo: Moderna, 2011.

PIAGET, Jean. O Juízo Moral na Criança. 4. ed. São Paulo: Summus, 1994. [1932].

PIAGET, Jean. Os Procedimentos da Educação Moral. Tradução: Maria Suzana de Stefano Menin. In: MACEDO, Lino de. Cinco Estudos de Educação Moral. São Paulo: Casa do Psicólogo, 1996. P. 1-36. [1930].

RAMOS, Marise Nogueira. Concepção de Ensino Médio Integrado. Curitiba: Secretaria de Educação do Estado do Paraná, 2008. Disponível em: <https://tecnicadmiwj.files.wordpress.com/2008/09/texto-concepcao-do-ensino-medio-integrado-marise-ramosl.pdf>. Acesso em: 04 out. 2017.

SÁNCHEZ VÁZQUEZ, Adolfo. Ética. Tradução: João Dell’Ana. 23. ed. Rio de Janeiro: Civilização Brasileira, 2002.

Vinícius Bozzano Nunes é doutorando em Educação na Universidade Estadual Paulista (UNESP); Mestre em Educação pela Universidade Federal do Mato Grosso (UFMT); Especialista em Bioética UFLA. Docente EBTT no Instituto Federal do mato Grosso do Sul (IFMS) campus Coxim.

E-mail: vinicius.nunes@ifms.edu.br

Leonardo Lemos de Souza é doutor em Educação pela Universidade Estadual de Campinas (UNICAMP); Psicólogo e Mestre em Educação na Universidade Estadual Paulista (UNESP). Estágio Pós-doutoral na Universitat de Barcelona. Docente departamento de psicologia UNESP Assis.

E-mail: leo.lemos.souza@gmail.com 